\title{
Estado Constitucional de Direito: breves considerações sobre o Estado de Direito
}

\author{
João Nunes Morais Junior ${ }^{1}$
}

\section{Resumo}

Este artigo pretende fazer uma brevíssima abordagem acerca da evolução do Estado de Direito, passando por sua concepção liberal e social até a incorporação de seus aspectos democrático e constitucional.

Palavras-Chave: Estado; Direito; Liberal; Social; Democrático; Constituição; Supremacia.

\section{Introdução}

Abordaremos no presente estudo, de modo breve, os desdobramentos da construção moderna de Estado até os dias atuais, chegando ao modelo do Estado constitucional de direito, que possui, como característica central, a afirmação da força normativa da constituição como carta incorporadora de reais vínculos destinados ao exercício do poder estatal.

Partimos da noção de Estado moderno passando pelo advento do Estado liberal e social de direito para, por fim, abordarmos a noção de Estado democrático de direito e Estado constitucional de direito.

Pretendemos, com o presente artigo, trazer os estudos por nos realizados com o fim de, possivelmente, servir de auxílio àqueles que iniciam o estudo do assunto. No entanto, ciente de que a abordagem feita apenas constituiu uma singela explanação sobre a matéria, carecendo de maiores aprofundamentos.

\section{Estado Liberal de Direito}

Hoje, entendemos a figura do Estado como ente submetido as suas próprias normas e cuja estrutura, limitações e imposições encontram-se em uma carta legal que o constitui, ou seja, a constituição.

1 Advogado, formado pela Universidade Estadual de Londrina. 
Esse modelo de Estado, contudo, possui uma evolução gradual objeto de diversos embates ideológicos até a sua configuração. Portanto, para a compreensão de sua atual composição é necessário que se faça uma breve abordagem histórica na evolução do conceito de Estado de direito.

O Estado de direito tem sua consagração com a afirmação do princípio da legalidade como meio limitador do poder, o que ocorreu sob a influência liberal incorporada à concepção de Estado, sobretudo, com a Revolução Francesa de 1789. Apesar da construção deste modelo ter suas origens muito antes da instauração da república em França. Antes disso, porém, é preciso mencionar outro modelo de Estado que vigorava até então.

A construção do Estado moderno, a partir de fins da idade média, apresentou-se primeiramente como um modelo de tipo absolutista, em que a centralização do poder, elemento caracterizador do Estado moderno, estava presente na figura do monarca (soberano), a quem cabiam todas as decisões relativas aos assuntos públicos.

Neste período, o Estado, como criador da ordem jurídica, não se submetia a ela: o poder era exercido segundo os interesses do monarca e as decisões tomadas pelo soberano deveriam ser acatadas (eram impostas).

O Estado Absolutista, já no século XVIII, foi marcado pela existência de um "mundo de privilégios da feudalidade decadente" (BONAVIDES, 2004, p. 42), os quais, juntamente com a amplitude dos poderes da coroa, a burguesia revolucionária posteriormente cuidou de destruir.

O momento histórico tido como marco da derrubada do regime absolutista foi a Revolução Francesa, fortemente influenciada pelas teorias liberais, sobretudo as de Locke e Montesquieu, que serviriam de base para o surgimento do novo modelo de Estado.

Apesar de não ter sido o primeiro fato histórico influenciado pelas idéias liberais, a Revolução Francesa foi um dos mais expressivos e de conseqüências bastante profundas e determinantes para a construção da idéia de um Estado de direito².

2 Chauí (1997, p. 402) destaca que "Na Inglaterra, o liberalismo se consolida em 1688, com a chamada Revolução Gloriosa. No restante da europa, será preciso aguardar a Revolução Francesa de 1789. Nos Estados Unidos consolida-se em 1776, com a luta pela independência. [...] As idéias políticas liberais tem como pano de fundo a luta contra as monarquias absolutistas por direito divino dos reis, derivadas da concepção teocrática de poder. O liberalismo consolida-se com os acontecimentos de 1789, na França, isto é, a Revolução Francesa, que derrubou o Antigo Regime". 
Com a exigência de uma autoridade que respeitasse principalmente a liberdade dos cidadãos e que impedisse a concessão de privilégios ${ }^{3}$, tais como eram concedidos à nobreza, veio à tona a Revolução Francesa em 1789.

A insustentabilidade do modelo absolutista resultou na instauração de um novo modelo de Estado, com novas exigências e que possuía como pressuposto não mais a sujeição do súdito ao arbítrio ou interesses do monarca, e sim a sujeição do cidadão ao governo das leis provenientes de uma assembléia da qual participavam (pelos menos indiretamente). Assim, houve a consolidação das teorias liberais que vieram a informar o novo modelo de Estado existente.

A consolidação desse novo modelo e seus pressupostos impunha que o Estado possuísse uma ordem normativa em função da qual o próprio poder político estaria limitado, ou seja, exigiu-se que a política fosse o exercício de uma ação normatizada, o que resultou na elaboração da idéia do Estado de direito. Nesse sentido, Bonavides (2004, p. 41) evidencia que

Foi assim - da oposição histórica e secular, na Idade Moderna, entre a liberdade do indivíduo e o absolutismo do monarca - que nasceu a primeira noção de Estado de Direito, mediante um ciclo de evolução histórica e decantação conceitual [...] A pugna decide-se no movimento de 1789 , quando o direito natural da burguesia revolucionária investe no poder o terceiro estado.

Essa manifestação do Estado de direito era desenhada sobre uma concepção eminentemente liberal ${ }^{4}$, que exigia o condicionamento da força do Estado à liberdade do

\footnotetext{
Hobsbawn (1996, pp. 75-76) afirma que na França do século XVIII, cerca de 40 mil pessoas dos 23 milhões de franceses compunham a nobreza que formava a linha privilegiada da 'nação', pois gozavam de isenções de impostos e do direito de receber tributos feudais. Se não fosse assim, economicamente, os nobres dependeriam somente da renda de suas propriedades ou de casamentos milionários, pensões, presentes ou sinecuras da corte, o que não cobriria os altos gastos exigidos pelo status de nobre. Dessa forma, os nobres naturalmente usavam seus privilégios para garantirem seus ganhos. Eles invadiam os postos oficiais ocupados pela classe média e usavam seus direitos feudais para extorquir dinheiro do campesinato. Agindo assim, a nobreza atingia não só a classe média mas também os campesinos (que compunham a maior parte da população francesa, cerca de $80 \%$, e que possuíam terras em quantidade insuficiente para o seu sustento).

4 Streck e Morais (2001, p. 50) afirmam que: "Pensamos poder situar o liberalismo como uma doutrina que foi-se forjando nas marchas contra o absolutismo onde se situa o crescimento do individualismo que se formula desde os embates pela liberdade de consciência (religiosa). Todavia, isso avança nas doutrinas dos direitos e do constitucionalismo, este como garantia(s) contra o poder arbitrário, da mesma forma que contra o exercício arbitrário do poder legal”.
} 
cidadão apoiada no princípio da legalidade e, dessa forma, subordinando as funções do Estado às decisões de uma assembléia legislativa da qual participavam os cidadãos ${ }^{5}$.

Houve, assim, a transferência da concentração das decisões das mãos do monarca, tal como existia no modelo absolutista de Estado, para a lei, ato da assembléia legislativa. Segundo Canotilho (2003, p. 95-96)

A primazia da lei servira para a submissão ao direito do poder político 'sob um duplo ponto de vista': (1) os cidadãos têm a garantia de que a lei só pode ser editada pelo órgão legislativo, isto é, órgão representativo da vontade geral (cfr. Déclaration de 1789, artigo 60); (2) em virtude de sua dignidade - obra dos representantes da Nação - a lei constitui a fonte de direito hierarquicamente superior (a seguir às leis constitucionais) e, por isso, todas as medidas adotadas pelo poder executivo a fim de lhe dar execução deviam estar em conformidade com ela (princípio da legalidade da administração) (grifo do autor).

Neste movimento, a concepção liberal foi incorporada ao Estado e, desde então, "apresenta-se como uma limitação jurídico-legal negativa, ou seja, como garantia dos indivíduos-cidadãos frente à eventual atuação do Estado, impeditiva ou constrangedora de sua atuação cotidiana" (STRECK; MORAIS, 2001, p. 91).

Ao Estado liberal, caberia a função de garantir a segurança e paz, ou seja, de assegurar a ordem pública, abstendo-se o máximo possível da intervenção na vida econômica e social dos indivíduos (CHAUI, 1997, p. 402).

A implementação do Estado jurídico, calcado nas teorias liberais, viu-se diante da necessidade de promover um quadro que garantisse o respeito à legalidade e assegurasse os direitos inatos do homem. A limitação ao poder do Estado caberia, de forma muito expressiva, à técnica de divisão dos poderes, ou seja, caberia aos órgãos estatais que, tendo suas funções diferenciadas, limitar-se-iam reciprocamente ${ }^{6}$.

A afirmação de que só a autoridade legisladora é competente para determinar a ordem jurídica que irá assegurar a proteção do indivíduo direcionou o foco da função

5 Marinoni (2005) destaca que "O Estado Liberal de Direito, diante da necessidade de condicionar a força do Estado à liberdade da sociedade, erigiu o princípio da legalidade como fundamento para a sua imposição. Esse princípio elevou a lei a um ato supremo com a finalidade de eliminar as tradições jurídicas do Absolutismo e do Ancien Regime. A administração e os juízes, em face desse princípio, ficariam impedidos de invocar qualquer direito ou razão pública que se chocasse com a lei".

6 Bonavides (2004, p. 71-72) destaca que “Antes, porém, que a realidade contradissesse aquele majestoso sistema de idéias ou pusesse abaixo aquele esboço otimista de organização social, em que a razão humana anunciava, no plano teórico, a obra de perfectibilidade das instituições, tudo levava a crer no triunfo dos esquemas de técnica constitucional do liberalismo. Um desses esquemas foi o da divisão dos poderes [...]". 
limitadora para o Legislativo, o que resultou na sua 'primazia' em relação aos demais órgãos do Estado.

Essa manifestação do Estado jurídico erigiu-se como modelo valendo-se também do argumento de uma nova autoridade soberana: a idéia do povo (cidadãos) soberano disposto a defender a sua liberdade inata.

Porém, com a implementação deste novo modelo de Estado, o ideal de universalização do regime democrático restou somente proclamado, sem ser efetivado de fato, o que se deveu principalmente à restrição do sufrágio censitário, o qual se concentrou nas mãos de uma classe. Chauí (1997, p. 404) afirma que

Podemos observar, portanto, que a idéia de contrato social, pelo qual os indivíduos isolados se transformam em multidão e esta se transforma em corpo político de cidadãos, não previa o direito à cidadania para todos, mas delimitava o contrato ou pacto a uma classe social, a dos proprietários privados ou burguesia.

Neste contexto, as constituições liberais caracterizavam-se por sua brevidade, calcada, sobretudo, na preocupação de conservar a esfera inviolável da iniciativa privada (BONAVIDES, 1997, p. 204).

Mais tarde, o referido deslocamento da soberania para as mãos do povo veio a ser objeto de busca pelo modelo do Estado social de direito, que incorporou também o aspecto social às constituições.

A partir de meados do século XIX, começaram a ocorrer mudanças na concepção liberal de Estado, redirecionando suas funções e incorporando, além da manutenção da paz e da segurança, algumas tarefas (prestações públicas) que deveriam ser realizadas.

O modelo liberal viu-se diante das exigências das idéias socialistas que reivindicavam maior igualdade econômica e social, para além da igualdade perante a lei, manifestada na generalidade das leis decorrente das idéias liberais. Surgiu assim o Estado social de direito.

\section{0 estado Social de Direito}

O Estado de direito sofre, então, uma mudança: da concepção eminentemente individualista de centralidade política passara-se a uma concepção social. 
Nas palavras de Bonavides (1997, p. 190), desloca-se "a idéia política da polaridade individual para a polaridade social". As exigências de saúde, educação, moradia e emprego, informadas pelas idéias socialistas, vieram a consolidar no início do século XX o que se chamou de Estado do Bem-Estar Social, incumbido de promover a melhoria das condições de vida da população.

No século XIX, o modelo liberal se expandiu e houve várias modificações nas estruturas econômica, social e política da Europa. Em conseqüência, Bonavides descreve que

pôs-se fim à escravidão, incapacidades religiosas (tolerância), inaugurou-se a liberdade de imprensa, discurso e associação e a educação foi estendida; o sufrágio foi se estendendo até a universalização; constituições escritas foram elaboradas; o governo representativo consolidou-se como modelo; garantiu-se o livre comércio e eliminaram-se taxações até então impostas, etc. (STRECK; MORAIS, 2001, p. 58).

Com a delimitação da ação do Estado, segundo o ideal liberal, a um campo restrito, logo surgiram massas inteiras desatendidas em suas necessidades materiais, o que levou à reivindicação do direito de igualdade (levantado apenas formalmente pelo ideal liberal) e à exigência de que o Estado realizasse algumas prestações a fim de estabelecer a igualdade social. De tal modo que somente com a implementação da igualdade social poderia ser exercida a liberdade pelo indivíduo ${ }^{7}$.

Segundo Bonavides (2004, p. 60-61),

No liberalismo, o valor liberdade, segundo Vierkandt, cinge-se a exaltação do indivíduo e de sua personalidade, com a preconizada ausência e desprezo da coação estatal [...] Leva Vierkandt seu pensamento as ultimas conseqüências ao afirmar que seria correto o conceito de liberdade do liberalismo se os homens fossem dotados de igual capacidade. Mas, como a igualdade a que se arrima o liberalismo é apenas formal, e encobre, na realidade, sob o manto da abstração, um mundo de desigualdades de fato - econômicas, sociais, políticas e pessoais -, termina 'a apregoada liberdade como Bismarck já o notara, numa real liberdade de oprimir os fracos, restando a estes, afinal de contas, a liberdade de morrer de fome.

7 Marinoni (2005) desta: “A neutralidade ou falta de conteúdo da lei e da jurisdição - ou, enfim, do próprio Estado legislativo - rapidamente fez perceber que a igualdade social constituía requisito para a efetivação da própria liberdade, ou melhor para o desenvolvimento da sociedade. Conclui-se, em síntese, que a liberdade somente poderia ser usufruída por aquele que tivesse o mínimo de condições materiais para ter uma vida digna". 
O Estado liberal considerava como cidadãos apenas os homens livres e independentes, o que correspondia dizer que homens dependentes e não-livres eram os que não possuíam propriedade privada. Portanto, estavam excluídos do poder político tanto os trabalhadores quanto as mulheres, que significavam a maioria da população.

Deste modo, desde o século XVIII até os dias atuais, lutas populares reivindicam a participação política tanto dos trabalhadores quanto das mulheres (CHAUI, 1997, p. 403404).

A inclusão dos não possuidores de patrimônio (propriedade) como participantes do processo político-eleitoral criou uma suscetibilidade por parte dos governantes em atender as reivindicações sociais. Segundo Streck e Morais (2001, p. 59-60),

\begin{abstract}
na medida em que o sufrágio se estendeu a novos setores sociais, os partidos políticos começaram a surgir, buscando votos de modo a governar na base do que ofereciam ao eleitorado, tornando os governos suscetíveis às solicitações populares, o que vai impor uma mudança de rota no projeto do Estado Mínimo no sentido de intervenção do poder público estatal em espaços até então próprios da iniciativa privada. $O$ espaço interventivo da ação estatal se expressa através de leis de pobreza para manter os desamparados; oficinas públicas para resolver o desemprego; legislação sobre o trabalho de menores - jornada de trabalho (10 horas em 1846, na Inglaterra); leis trabalhistas relativas à segurança do trabalho, propagando-se movimentos de autodeterminação e independência.
\end{abstract}

O Estado, portanto, incorpora algumas funções, reveladas em prestações positivas a serem realizadas com vistas à implementação da igualdade social, de modo que o Estado social de direito se revela em "um tipo de Estado que tende a criar uma situação de bemestar geral que garanta o desenvolvimento da pessoa humana" (SILVA, 2003, p. 115).

O embate que se formou nas tentativas de conciliação entre o Estado liberal, em crise, e o Estado social, em ascensão, foi grande. A tentativa de reconciliar as normas constitucionais eminentemente liberais com a sociedade, a princípio, implicava o sacrifício das teses individualistas. Tal embate ideológico encontrou conciliação com a introdução de fórmulas programáticas dentro dos textos constitucionais, criação esta cuja expressão maior foi a Constituição da República de Weimar.

Com as normas programáticas, temia-se que a constituição perdesse o seu caráter jurídico vinculativo, perdendo sua normatividade e transmutando-se em recomendação política. A Constituição de Weimar, com suas incertezas, permitiu, por via programática, a primeira abertura para os direitos sociais. 
Bonavides afirma que, no constitucionalismo contemporâneo, há o debate para se afirmar o caráter normativo ou não das normas programáticas, dizendo que é necessário reconhecer a eficácia vinculante das normas programáticas a fim de que seja reconhecida a natureza jurídica da constituição, não havendo constituição sem força cogente, e acrescenta que

atribuindo-se eficácia vinculante à norma programática, pouco importa que a Constituição esteja ou não repleta de proposições desse teor, ou seja, de regras relativas a futuros comportamentos estatais. O cumprimento do cânones constitucionais pela ordem jurídica terá dado um largo passo à frente. Já não será fácil com respeito à Constituição tergiversar-lhe a aplicabilidade e eficácia das normas como os juristas abraçados à tese antinormativa, os quais, alegando programaticidade de conteúdo, costumam evadir-se ao cumprimento ou observância de regras e princípios constitucionais. [...] Afigura-se-nos que a compreensão correta das normas programáticas como normas jurídicas contribui consideravelmente para reconciliar os dois conceitos da histórica crise constitucional de dois séculos: o conceito jurídico e o conceito político de Constituição (BONAVIDES, 1997, pp. 211-212).

As lutas populares ampliaram os direitos civis: a participação política, a fiscalização do Estado por meio de organizações sociais (associações, sindicatos, partidos políticos), o direito à informação, etc., e com isso criaram os direitos sociais (trabalho, lazer, saúde, educação etc.) e os direitos das minorias (mulheres, idosos, negros, índios etc.). Por fim, a expansão do regime democrático assegurou a abertura ao campo social, à criação de novos direitos e à ampliação dos direitos já existentes.

\section{Estado Democrático de Direito e Estado Constitucional de Direito}

A preocupação social incorporada ao Estado não foi suficiente para apresentar solução ao problema da igualdade, pois esta se funda, desde o conceito clássico (liberal) de Estado de direito, na generalidade das leis, elemento formal e abstrato que não implica uma alteração da situação concreta da sociedade com vista à implementação da igualdade.

Assim, ganhou destaque a preocupação de fomentar a participação pública, a participação crescente no processo decisório e na formação dos atos de governo, tendo em mente a participação igualitária.

Incrementa-se, portanto, a preocupação com a caracterização democrática do Estado, de tal forma que 
se desenvolve um novo conceito, na tentativa do conjugar o ideal democrático ao Estado de Direito, não como uma aposição de conceitos, mas sob um conteúdo próprio onde estão presentes as conquistas democráticas, as garantias jurídicolegais e a preocupação social. Tudo constituindo um novo conjunto onde a preocupação básica é a transformação do status quo. (STRECK; MORAIS, 2001, p. 92, grifo do autor).

A mudança que ocorrera na concepção do Estado liberal de direito não se restringiu apenas ao papel a ser desempenhado pelo Estado, que com a agregação do elemento social passou a realizar algumas prestações, mas também promoveu a busca de ampliação da participação do povo na coisa pública e, por conseguinte, na reconceitualização do principal mecanismo de atuação do Estado, ou seja, a lei (STRECK; MORAIS, 2001, p. 92). Esta passou a possuir a função ideal de transformação da realidade, dada a abertura que a democracia contemporânea apresenta para a ampliação dos direitos já existentes, bem como para a criação de novos direitos.

O aspecto democrático leva em consideração a abertura do campo social para a ampliação de direitos. Chauí aponta dois traços próprios que distinguem a democracia de todas as formas sociais e políticas:

1. A democracia é a única sociedade e o único regime político que considera o conflito legítimo. Não só trabalha politicamente os conflitos de necessidades e de interesses (disputas entre os partidos políticos e eleições de governantes pertencentes a partidos opostos), mas procura instituí-los como direitos e, como tais, exige que sejam reconhecidos e respeitados. Mais do que isso. Na sociedade democrática, indivíduos e grupos organizam-se em associações, movimentos sociais e populares, classes se organizam em sindicatos e partidos, criando um contra-poder social que, direta ou indiretamente, limita o poder do Estado;

2. a democracia é a sociedade verdadeiramente histórica, isto é aberta ao tempo, ao possível, ás transformações e ao novo. Com efeito, pela criação de novos direitos e pela existência dos contra-poderes sociais, a sociedade democrática não está fixada numa forma para sempre determinada, ou seja, não cessa de trabalhar suas divisões e diferenças internas, de orientar-se pela possibilidade objetiva (a liberdade) e de alterar-se pela própria praxis. (CHAUI, 1997, p. 433, grifos do autor).

Ao se buscar o ideal democrático, a legitimação democrática do poder deu-se pela implementação do princípio da soberania popular, segundo o qual se permitiria a igual participação na formação da vontade do Estado. E, por assim ser, isso implicou a busca da participação do povo na coisa pública, ou seja, a busca da instauração de um processo de efetiva incorporação de todo o povo no controle das decisões. 
Dessa forma, tal como José Afonso da Silva (2003, p. 122) descreve, o Estado democrático de direito funda-se nos seguintes princípios:

(a) princípio da constitucionalidade, que exprime, em primeiro lugar, que o Estado Democrático de Direito se funda na legitimidade de uma constituição rígida, emanada da vontade popular, que, dotada de supremacia, vincule todos os poderes e os atos deles provenientes, com as garantias de atuação livre de regras da jurisdição constitucional;

(b) princípio democrático, que, nos termos da Constituição, há de constituir uma democracia representativa e participativa, pluralista, e que seja a garantia geral de vigência e eficácia dos direitos fundamentais (art. 1);

(c) sistema de direitos fundamentais, que compreendem os individuais, coletivos, sociais e culturais (títulos II, VII e VIII);

(d) princípio da justiça social, referido no art. 170, caput, e no art. 193, como princípio da ordem econômica e da ordem social; [...] a Constituição não prometeu a transição para o socialismo mediante a realização da democracia econômica, social e cultural e o aprofundamento da democracia participativa, como o faz a Constituição portuguesa, mas com certeza ela se abre também, timidamente, para a realização da democracia social e cultural, sem avançar significativamente rumo à democracia econômica;

(e) princípio da igualdade (art. 5, caput, e I);

(f) princípio da divisão dos poderes (art. 2) e da independência do juiz (art. 95);

(g) princípio da legalidade (art. 5, II);

(h) princípio da segurança jurídica (art. 5, XXXVI a LXXIII).

O Estado democrático de direito modifica o conteúdo do princípio da legalidade, se comparado com aquele que regia o Estado de direito clássico. Neste, a lei estabeleceria a igualdade por ter como característica a generalidade, pois sendo geral seria regra para todos.

A generalidade das leis e o abstencionismo do Estado, características do Estado liberal de direito, resultaram em desigualdades materiais, tal como foi dito na caracterização do Estado social de direito, havendo a necessidade de que as leis realizassem efetivas intervenções a fim de que fosse alterada a situação concreta da sociedade.

Peña Freire observa que

A lei, como norma geral e abstrata, pressuporia uma sociedade homogênea de homens livres e iguais. Só neste contexto era possível a regulação integral da vida jurídica com umas poucas normas, preferentemente codificadas, muito gerais e que, também, por sua abstração se Ihes suporia vocação de permanência quando não pretensão de inamovibilidade temporal ${ }^{8}$. (tradução livre)

8 “La ley como norma general y abstracta pressuponia una sociedad homogénea de hombres libres e iguales. Sólo en este contexto social era posible la regulación integral de la vida jurídica con unas pocas normas, 
No Estado democrático de direito, a lei deve buscar a alteração de situações concretas com vistas à igualdade. Assim, a lei veio a ter, sobretudo, a função de concretização dos valores socialmente estabelecidos nas constituições e, assim sendo, a de implementar reais modificações. Nesse sentido, Silva (2003, p. 121-122) destaca que

\begin{abstract}
a lei não deve ficar numa esfera puramente normativa, não pode ser apenas lei de arbitragem, pois precisa influir na realidade social. E se a Constituição se abre para transformações políticas, econômicas e sociais que a sociedade brasileira requer, a lei se elevará de importância, na medida em que, sendo fundamental expressão do direito positivo, caracteriza-se como desdobramento necessário do conteúdo da Constituição e aí exerce função transformadora da sociedade, impondo mudanças sociais democráticas, ainda que possa continuar a desempenhar uma função conservadora, garantindo a sobrevivência de valores socialmente aceitos.
\end{abstract}

Dentro deste contexto, também se apresenta o Estado constitucional de direito que, para além do Estado de direito clássico, é caracterizado por possuir três fatores relevantes:

a) a supremacia da constituição, e, dentro desta, dos direitos fundamentais, sejam de natureza liberal ou social;

b) a consagração do princípio da legalidade como subsunção efetiva de todos os poderes públicos ao direito; e

c) a 'funcionalização' de todos os poderes do Estado para garantir o desfrute dos direitos de caráter liberal e a efetividade dos direitos sociais (FREIRE, 1997, p. 37).

A supremacia constitucional está ligada à idéia de afirmação da normatividade constitucional e, com isso, da efetiva vinculação dos poderes públicos às normas constitucionais.

Na afirmação de que o poder está submetido ao direito e de que a lei geral e abstrata, como expressão do poder, tem que ter sua origem na vontade geral, encontra-se o instrumental de garantia que o Estado de direito clássico (liberal) dispensa aos indivíduos frente ao poder político.

A lei, dentro nesse aspecto, é a melhor forma de garantia do indivíduo frente ao poder, pois este não poderá atuar a margem da lei, mas apenas dentro de seus limites; e a 
lei também é o instrumento mais idôneo para garantir as liberdades individuais, pois é por meio dela que o povo converte-se na voz que pronuncia o direito.

A justificação histórica e racional da autoridade do poder, entretanto, agora não mais embasada na figura da autoridade divina (Estado absolutista), terminou criando uma imagem irreal do Estado, proclamado integrador, igualitarista e orientado à garantia da vida, da propriedade e da liberdade dos indivíduos.

Com isso, o direito também foi afastado de qualquer referência substancial ou material, passando a ser um molde cujo conteúdo irá ser preenchido pelas decisões políticas. O resultado disso, afirma Peña Freire, acabou por desmantelar o potencial garantista da lei como limite do poder, de forma que

o absolutismo monárquico avançará à um sistema organizativo onde a supremacia política e jurídica passa às mãos do Poder Legislativo, único soberano a ser representante da nação. se o império da lei era considerada a garantia máxima contra o arbítrio e a injustiça dos governantes, uma vez assentado o modelo jurídico-político burguês, assistiremos a um giro na realidade do Estado de direito, que abrirá as portas a novas expressões absolutas ou totais de poder. Em suma, superado o poder absoluto do rei, este foi substituído pelos das assembléias soberanas, e, portanto, ao absolutismo monárquico sucede uma situação de absolutismo legislativo ou concepção absoluta de lei, à que resulta finalmente assimilada a própria idéia de direito ${ }^{9}$. (tradução livre)

No Estado de direito liberal, o foco de controle do poder ficou centrado no Parlamento. Sendo assim, a constituição não representava o principal foco de limitação do poder, mas sim a assembléia legisladora, que cumpriria a função de frear os eventuais abusos no exercício do poder. A supremacia da constituição não se traduzia em supremacia de fato.

Canotilho (2003, p. 96) afirma que

a limitação do poder pelo direito acabaria, em França, numa situação paradoxal. A supremacia da constituição foi neutralizada pela primazia da lei. Daí que um

9 “el absolutismo monárquico dará paso a un sistema organizativo donde la supremacía política y jurídica pasa a manos del poder legisltivo, único soberano al ser representante de la nación. Si el império de la ley era considerado la garantía máxima contra el arbítrio y la injusticia de los governantes, una vez assentado el modelo jurídico-político burgués, asistiremos a un giro en la realidad del Estado de derecho, que abrirá las puertas a nuevas expressiones absolutas ou totales de poder. En definitiva, superado el poder absoluto del rey, éste fue sustituido por el de las asembleas soberanas, y, por lo tanto, al absolutismo monárquico sucede una suerte de absolutismo legislativo o concepción obsoluta de la ley a la que queda finalmente asimilada la propria idea de derecho" (FREIRE, 1997, p. 53). 
célebre jurista francês [J. Acosta Sanchez] se tenha referido ao 'Estado de direito francês' como um Estado legal ou Estado de legalidade relativamente eficaz no cumprimento do princípio da legalidade por parte da administração mas incapaz de compreender o sentido da supremacia da constituição, à imagem do paramount law americana, e insensível à força normativa dos direitos e liberdades 'declarados' logo na Déclaracion de 1789. Dir-se-ia que a bondade do constitucionalismo francês quanto à idéia de sujeição do poder ao direito radica mais na substância de suas idéias (constituição, direitos) do que na capacidade de engendrar procedimentos e processos para lhes dar operatividade prática. Não sem razão, se fala do constitucionalismo francês como um 'constitucionalismo sem Constituição'.

O Estado legislativo (Estado de direito clássico), portanto, mesmo tendo presente a figura da constituição como carta limitadora do poder, não foi capaz de cumprir o seu propósito limitador.

Assim, para assegurar a subsunção de todos os poderes públicos ao direito, foi afirmada a supremacia constitucional e o caráter plenamente normativo das constituições, como forma de reforçar a máxima vinculação de todos os poderes do Estado e de sua produção normativa ao direito.

A passagem do Estado legislativo para o Estado constitucional pressupõe a afirmação do caráter normativo das constituições, que integram um plano de juridicidade superior, vinculante e indisponível para todos os poderes do Estado. Peña Freire afirma que "essa refundação ou configuração do ordenamento jurídico, não supõe, no fundo, senão um redimensionamento do princípio da legalidade" ${ }^{10}$.

Esse redimensionamento do princípio da legalidade equivale dizer que só serão Estados de direito aqueles modelos político-institucionais que incorporam uma série de limites ou vínculos materiais como condição de validade da norma e possibilidade de expressão do poder político (FREIRE, 1997, p. 58). Características estas de um efetivo governo sub lege, no qual a relação do poder com os cidadãos exige o atendimento de determinadas exigências, tanto formais quanto substanciais, para que a norma seja válida e possa obrigar, o que é próprio do Estado constitucional de direito (CADERMARTORI, 1999, p. 24-34 passim).

Esse Estado constitucional de direito, portanto, assegura a centralidade da pessoa humana e a garantia de seus direitos fundamentais como vínculos estruturais de toda a dinâmica política que implica o princípio democrático.

10 "esta refundación o configuración del ordenamiento jurídico no supone, en el fondo, sino un redimensionamento del princípio da legalidad” (FREIRE, 1997, p. 58). 
No pacto fundante do Estado (constituição) são determinadas as questões absolutamente indispensáveis para a vida, que serão declaradas intangíveis por meio dos direitos fundamentais e de suas garantias. Daí a afirmação da 'funcionalização' dos poderes públicos em direção ao cumprimento dos direitos fundamentais (FREIRE, 1997, p. 78-79).

Neste sentido, as imposições constitucionais careceriam de efetividade se não houvesse um órgão que garantisse, em última instância, o seu cumprimento. O papel de destaque conferido ao Poder Judiciário dentro do Estado constitucional de direito consiste em ser o órgão garantidor deste cumprimento. Matteucci (2000, p. 256) aponta para tal função quando destaca que com a

\begin{abstract}
transposição do equilíbrio constitucional do legislativo para o judiciário, esta nova relação entre poder e direito indicam certamente uma ruptura com a nossa tradição política mais recente, uma ruptura que não é ainda plenamente clara para a nossa cultura política. Isto era necessário para o advento da democracia. No passado, a garantia contra o poder arbitrário se achava sobretudo nos corpos representativos que controlavam o Governo. Hoje, ao contrário, os corpos representativos exercem uma função de controle bastante mais reduzida [...]. Para se encontrar uma nova garantia contra o poder arbitrário, para tutelar os direitos dos cidadãos, é mister, portanto, recorrer à função judiciária, a única capaz de tornar efetiva a supremacia da lei sobre o Governo.
\end{abstract}

Os limites impostos ao exercício do poder que estão presentes na constituição nada valem se inexistem controles que garantam a sua eficácia. Se não existem meios para sua efetivação, ou se esses meios não são usados. Essa garantia constitucional se torna completamente ineficaz, ficando reduzida à pura retórica política ou a um simples limite moral se não for assegurada a sua implementação.

A supremacia constitucional atribui à constituição função de ser a norma conformadora da ordem jurídica. De modo que a produção normativa decorre da própria constituição e é nesta, portanto, que se encontra o fundamento de validade, tanto formal como substancial, das normas do Estado. Isso permite dizer que, no exercício da atividade jurisdicional, a subordinação à legalidade existe somente em função de leis que atendam as formas limites e os conteúdos determinados pela constituição. Ao Poder Judiciário, portanto, caberá, em último caso, a função de aproximar o modelo normativo existente na constituição da prática efetiva do Estado, função esta a ele atribuída pelo próprio modelo do Estado constitucional de direito. 


\section{Conclusão}

A evolução do conceito de Estado de direito, de sua fundação até os dias atuais, é de suma importância para o estudo do direito, pois, além da compreensão do conceito, ajuda a situar-se na conjuntura atual da estrutura estatal.

Os vários passos seguidos na tentativa de construir um modelo de Estado influenciaram também os vários sentidos agregados à expressão Estado de direito.

Primeiramente, de cunho ideológico eminentemente liberal, o Estado de direito (Estado liberal de direito) foi designado como estado submetido as suas próprias leis. Isso porque a preocupação da época estava em superar o modelo de Estado absolutista, limitando a sua intervenção na liberdade individual e relegando os principais aspectos públicos de governo às leis provenientes de um Parlamento composto pelos considerados cidadãos na época.

Em seguida, a ausência do Estado em determinados âmbitos da vida social relegou grande parte da população a uma situação de séria desvantagem em relação à outra pequena parte efetivamente participante das decisões políticas do Estado. Fato este que tornou insustentável o modelo liberal de Estado praticado, dando espaço à incorporação de aspectos da ideologia socialista pelo modelo estatal na medida em que o próprio exercício da liberdade ficaria suprimido se não houvesse um mínimo de condições materiais de subsistência para exercê-la. Passa-se, então, à admissão de obrigações (pretações positivas), impostas pelas leis (Estado social de direito), a serem realizadas pelo Estado.

Assim, ao conceito eminentemente liberal de Estado de direito agregou-se o aspecto social. Contudo, não era somente com a imposição da realização de determinadas prestações que estaria completo o modelo estatal, era preciso que o povo efetivamente participasse das decisões políticas. Essa busca pela democracia aparenta ser inatingível e até os dias atuais é também pretendida, de tal forma que a concretização do Estado democrático de direito sempre está sendo buscada.

Nesse contexto, também se insere a noção de Estado constitucional de direito.

A concepção liberal de Estado inicialmente pretendeu, e efetivamente o fez, retirar o poder político das mãos do monarca (Estado absolutista) e, para isso, apresentou a justificativa racional para a existência da organização estatal, valendo-se principalmente das teorias contratualistas de Locke e Montesquieu. Deste modo, ressaltou-se a importância do 
Parlamento tendo em vista, agora, o governo de leis, aprovadas pelos cidadãos e não mais provenientes do arbítrio do monarca.

Com isso, a figura da Assembléia Legislativa ganhou principal destaque na vida política estatal e, mesmo existindo constituição, o seu papel ficava em segundo plano.

A incorporação das conquistas históricas de direitos (liberdades, prestações, democracia etc) nas constituições não possuía muita efetividade tendo em vista que o poder decisivo estava na Assembléia Legislativa. Em razão de tal circunstância (e da conjuntura), cada vez mais se busca afirmar o caráter normativo da constituição a fim de lhe dar efetividade.

Em decorrência dessa afirmação de normatividade da constituição, a relação entre poder político e direito teve um novo enfoque: a passagem do Estado legislativo para o Estado constitucional. O que implica a transferência da garantia contra o uso arbitrário do poder do Legislativo para o Judiciário, órgão este encarregado de assegurar a constituição e a unidade do ordenamento jurídico.

Portanto, no atual modelo de Estado constitucional de direito, o papel do Poder Judiciário é primordial na garantia dos direitos fundamentais (e de sua efetividade no plano social, por conseguinte). Não podendo tal Poder se escusar em assumir o seu papel, embora pareça que não é muito bem difundida essa atribuição entre os operadores do direito.

\section{Referências}

BONAVIDES, Paulo. Do Estado liberal ao Estado social. 7. ed. São Paulo: Malheiros, 2004. . Curso de direito constitucional. 7. ed. São Paulo: Malheiros, 1997.

CADEMARTORI, Sérgio. Estado de direito e legitimidade: uma abordagem garantista. Porto Alegre: Livraria do Advogado, 1999.

CANOTILHO, José Joaquim Gomes. Direito Constitucional e Teoria da Constituição. 7. ed. Coimbra/Portugal: Livraria Almedina, 2003.

CHAUI, Marilena de Souza. Convite à filosofia. 6. ed. São Paulo: Ática, 1997.

FREIRE, Antônio Manuel Peña. La garantía en el Estado constitucional de derecho. Madrid: Editorial Trotta, 1997. 
MARINONI, Luiz Guilherme. A jurisdição no Estado constitucional. Jus Navigandi, Teresina, v. 9, n. 635, 4 abr. 2005. Disponível em:

<http://www1.jus.com.br/doutrina/texto.asp?id=6550>. Acesso em: 12 abr. 2005.

MATTEUCCI, Nicola. Constitucionalismo. In: BOBBIO, Norberto et all. Dicionário de Política. 5. ed. Brasília: Editora Universidade de Brasília : São Paulo: Imprensa Oficial de São Paulo, 2000.

SILVA, José Afonso da. Curso de Direito Constitucional Positivo. 22. ed. São Paulo: Malheiros, 2003.

STRECK, Lenio Luiz; MORAIS, José Luis Bolsan. Ciência Política e Teoria Geral do Estado. 2. ed. Porto Alegre: Livraria do Advogado, 2001. 
